\title{
Unstable angina and exposure to carbon monoxide
}

\author{
M.V. Balzan, J.M. Cacciottolo and S. Mifsud
}

Department of Medicine, Saint Luke's Hospital, Malta

\begin{abstract}
Summary: Inhalation of small amounts of carbon monoxide diminishes the pain threshold in patients with stable angina pectoris. The aim of this study was to identify and describe patients who had been exposed unknowingly to toxic inhalations of this gas and subsequently presented to hospital with a clinical picture of unstable angina. Blood carboxyhaemoglobin levels of 104 patients referred with unstable angina to a coronary care unit were determined on admission. The likely source of carbon monoxide was identified in all patients. Three patients had definite carbon monoxide intoxication. Another five patients had evidence of minor exposure. When the three cases with carbon monoxide poisoning were excluded, the mean carboxyhaemoglobin level was $2.5 \%( \pm 1.3)$ for smokers $(n=30)$ and $0.6 \%( \pm 0.5)$ for non-smokers $(n=71)$. Use of fossil fuel combustion in an enclosed environment was responsible for the three most serious intoxications and one of the minor cases. We suggest that a number of patients admitted for coronary care with unstable angina may have significant carbon monoxide poisoning. This intoxication is often overlooked by attending physicians with the result that high concentration oxygen therapy is not administered, when it is in fact a necessary part of treatment.
\end{abstract}

\section{Introduction}

Emissions from motor cars and cigarette smoking are the most important sources of carbon monoxide inhalation. ${ }^{1}$ In many countries, butane gas or kerosene heaters are used extensively for home heating during the winter months and represent a potential source of carbon monoxide intoxication.

Overt carbon monoxide poisoning with carboxyhaemoglobin levels of over $40 \%$ tends to produce primarily a neurological picture with unconsciousness and upper motor neuron signs. ${ }^{1}$ In healthy subjects, myocardial toxicity occurs only with carboxyhaemoglobin levels of above $25 \%,{ }^{2.3}$ while definite myocardial subendocardial necrosis almost invariably occurs with levels above $50 \%$. ${ }^{4.5}$

In patients with coronary artery disease, blood carboxyhaemoglobin concentrations as low as $2 \%$ have been documented to lower the anginal pain threshold during treadmill exercise tests. This was more evident with carboxyhaemoglobin levels above $4 \%{ }^{6-10}$ It would be logical to suppose that carboxyhaemoglobin levels between 10 and $20 \%$ could precipitate unstable angina in patients with stable or asymptomatic coronary artery disease.

As carbon monoxide is an odourless gas, the patient and his attending physician are very often unaware of such toxic inhalation. As a result a patient might be admitted to a coronary care unit with unstable angina without this exposure being suspected. ${ }^{11}$ The main aim of our study was to identify such cases.

Correspondence: M.V. Balzan, M.D., M.R.C.P. (U.K.). Accepted: 5 May 1994

\section{Patients and methods}

The coronary care unit at Saint Luke's hospital is the only acute cardiology unit serving the whole of the island of Malta (population around 330,000). From the 1 December 1992 to the 30 April 1993, patients admitted with unstable angina to this unit were included in the study. Unstable angina was defined according to guidelines used by Theroux $e t$ $a l .^{12}$ Diagnosis was based on a clinical history of an accelerating pattern of chest pain occurring at rest or on minimal exertion, or of pain lasting more than $20 \mathrm{~min}$. In the absence of electrocardiographic changes compatible with ischaemia, the diagnosis was confirmed by two independent physicians. The most recent chest pain had to have occurred within $24 \mathrm{~h}$ of admission. In addition to Theroux's guidelines, angina of recent onset, that is one week or less, was also a criterion for inclusion.

Patients with definite electrocardiographic evidence of fresh myocardial infarction or a creatinine kinase of more than 200 units/litre (normal $<100$ ) on admission to the emergency room were excluded from the study. If evidence of myocardial infarction developed after admission to the coronary care unit the patient was retained in the study. Patients with anaemia were excluded (haemoglobin cut-off levels; $12 \mathrm{~g} / \mathrm{dl}$ for females, $14 \mathrm{~g} / \mathrm{dl}$ for males).

Blood samples were taken on admission to the emergency department. Carboxyhaemoglobin levels were determined using the IL 482 COoximeter. Two carboxyhaemoglobin calibration 
standards were used to check the calibration of the instrument. Besides basic demographic information, the average quantity of cigarettes smoked per day in the week prior to admission was recorded. History of stable angina, documented previous admission with acute myocardial infarction or definite electrocardiographic evidence of previous myocardial infarction was noted.

Patients were questioned about exposure to sources of carbon monoxide. Information was sought about use of gas and kerosene heaters, proximity to conflagration or motor vehicle emissions.

The approximate peak carboxyhaemoglobin level was calculated from the value measured on admission and the time interval between the end of the exposure and the time of blood sampling. A standard reference chart was used. ${ }^{1}$ The possible shortening of the half-life of carboxyhaemoglobin by oxygen given by the ambulance staff or in the emergency room was not included in the calculation. This factor could have led to lower estimated peak values of carboxyhaemoglobin. As carboxyhaemoglobin is stable at room temperature ${ }^{13}$ it was assumed there was no further decay after blood sampling. Coronary angiography was performed only at the discretion of the attending physician.

\section{Results}

A total of 104 cases of unstable angina were recruited into the study. Three cases described here had definite carbon monoxide intoxication. The mean carboxyhaemoglobin levels for smokers and non-smokers are shown on Table I. The features of patients with raised carboxyhaemoglobin are shown on Table II.

\section{Case 1}

A 71 year old man was admitted to the coronary care unit with retrosternal compressive chest pain at rest lasting 2 hours together with nausea and vomiting. He had evidence of widespread atherosclerosis but had not suffered previously from angina pectoris. Both femoral pulses were absent. His left arm had been amputated one year previously; until this time he had smoked 60 cigarettes a day.

On admission, his electrocardiogram (ECG) showed $3 \mathrm{~mm}$ ST segment depression in leads V2-V3. Carboxyhaemoglobin on admission was $15.2 \%$ and he was treated with $100 \%$ oxygen and intravenous isosorbide dinitrate. He recovered well

Table I Patients admitted with unstable angina

\begin{tabular}{lcc}
\hline & Smokers & Non-smokers \\
\hline Mean age (years) & 57 (s.d. 11) & 64 (s.d. 10) \\
Mean CO-Hb \% & 2.5 (s.d. 1.3) & 0.6 (s.d. 0.5) \\
Male $(n)$ & 25 & 56 \\
Female $(n)$ & 5 & 15 \\
Total $(n)$ & 30 & 71 \\
\hline
\end{tabular}

$\mathrm{CO}-\mathrm{Hb}=$ carboxyhaemoglobin.

Table II Patients with raised carboxyhaemoglobin levels

\begin{tabular}{|c|c|c|c|c|c|}
\hline Patient & $\begin{array}{l}\text { Carboxy } \\
\text { Measured }\end{array}$ & $\begin{array}{l}(\%) \\
\text { Peak }\end{array}$ & $\begin{array}{c}\text { Interval } \\
\text { exposure-admission } \\
\text { (hours) }\end{array}$ & Source & $\begin{array}{l}\text { Coronary } \\
\text { angiography }\end{array}$ \\
\hline 1 & 15.2 & 20 & 2 & Kerosene heater & Not done \\
\hline 2 & 7.5 & 15 & 6 & Kerosene heater & $\begin{array}{l}\text { Occluded L circum. } \\
\text { diag. } 75 \% \text { stenosis }\end{array}$ \\
\hline 3 & 10.1 & 15 & 3 & Kerosene heater & Not done \\
\hline 4 & 6.4 & $7-8$ & 1 & Smoker, traffic & Occluded L mainstem \\
\hline 5 & 4.8 & $6-8$ & 4 & Smoker in taxi & $\begin{array}{l}\text { LAD } 80 \% \text { stenosis, } \\
\text { circum. } 90 \% \text { stenosis, } \\
\text { RCA occluded }\end{array}$ \\
\hline 6 & 4.3 & $7-8$ & 6 & $\begin{array}{l}\text { Works at bus } \\
\text { terminus }\end{array}$ & $\begin{array}{l}\text { LAD } 90 \% \text { stenosis, } \\
\text { circum. } 90 \% \text { senosis, } \\
\text { RCA } 90 \% \text { stenosis }\end{array}$ \\
\hline 7 & 4.2 & $6-8$ & 3 & Cigarette smoke & $\begin{array}{l}\text { LAD } 75 \% \text { stenosis, } \\
\text { occluded circum. }\end{array}$ \\
\hline 8 & 2.6 & $6-8$ & 12 & Kerosene heater & LAD $90 \%$ stenosis \\
\hline
\end{tabular}

Carboxy-Hb = carboxyhaemoglobin; LAD = left anterior descending; circum. = circumflex; $\mathrm{RCA}=$ right coronary artery; diag. = diagonal branch. 
and there was no rise in the creatine kinase levels. $\mathrm{He}$ had used an old kerosene heater without appropriate ventilation for 12 hours before admission. His wife, a non-smoker, who had also complained of headache and nausea had a carboxyhaemoglobin level of $6.6 \% 10$ hours after cessation of exposure. Coronary angiography was not performed.

\section{Case 2}

A 55 year old non-smoker was admitted for coronary care with retrosternal compressive chest pain of 2 hours duration occurring at rest, and accompanied by nausea and vomiting. One year before this episode he had sustained an acute myocardial infarct with subsequent post-infarct angina. There were no fresh abnormalities on the ECG.

He was treated with intravenous isosorbide dinitrate. He recovered well and there was no cardiac enzyme rise. Carboxyhaemoglobin level on admission was $7.5 \%$. He admitted that up to 6 hours before his admission he had used a kerosene heater in a small and poorly ventilated flat. It was calculated that probably his peak carboxyhaemoglobin levels had been around $15 \%$. His wife's carboxyhaemoglobin taken 16 hours after cessation of exposure was $3.3 \%$. She was also a non-smoker. The patient's coronary angiogram showed a $75 \%$ stenosis of the diagonal branch of the left anterior descending artery, a totally occluded left circumflex artery and a normal right coronary artery.

\section{Case 3}

A 50 year old previously healthy non-smoker presented with fresh onset of angina pectoris. He described several episodes of typical retrosternal compressive chest pain on ascending one flight of steps. He also complained of headache, nausea and vertigo. ECG on admission showed no abnormality. He had used an old kerosene heater in an unventilated room for about 4 hours after which period he developed his symptoms. Carboxyhaemoglobin on admission, taken 3 hours after the exposure, was $10.1 \%$. Probably his peak levels had been around $15 \%$. He was treated with $100 \%$ oxygen. There was no cardiac enzyme rise or subsequent electrocardiographic abnormality. An exercise test using a modified Bruce protocol was negative. Coronary angiography was not performed.

\section{Discussion}

In this study, three out of 104 patients admitted with unstable angina had significant carbon monoxide exposure with peak carboxyhaemoglobin levels between $15 \%$ and $20 \%$. Cases 1 and 2 had strong evidence of coronary artery disease and this would explain why myocardial ischaemia became clinically relevant before the development of significant neurological manifestations.

We could only find two documented cases of carbon monoxide poisoning presenting as unstable angina. ${ }^{11,14}$ Our data would suggest that this should not be such a rare presentation. Probably this intoxication is usually overlooked by the admitting doctors, as happened in two of our cases.

As the purpose of this study was to identify the occasional sporadic case of carbon monoxide poisoning within the study group, rather than to establish an association between unstable angina and the mean carboxyhaemoglobin level, this level was not compared to that of a control group.

Furthermore, the liberal use of low concentration oxygen therapy in cases of unstable angina by ambulance and casualty personnel would have made such a case-control comparison very difficult to interpret. In fact, the mean carboxyhaemoglobin levels in both smokers and non-smokers in our study were lower than those reported in two studies on healthy volunteers. Stewart et al. ${ }^{13}$ who studied 29,000 blood donors, reported a mean carboxyhaemoglobin of $1.5 \%$ for non-smokers and $5 \%$ for smokers, while Cole et al. ${ }^{15}$ reported $5.9 \%$ (s.d. 2.6) carboxyhaemoglobin in smokers and of $1.6 \%$ (s.d. 0.6 ) in non-smokers.

However, while carboxyhaemoglobin levels of $2-10 \%$ are of no clinical relevance in healthy volunteers, it has been demonstrated that such levels can exacerbate myocardial ischaemia in patients with severe coronary artery disease. ${ }^{6-10}$

The commonest source of carbon monoxide inhalation was cigarette smoke. Atmospheric pollution is probably clinically most relevant amongst people working or living close to major traffic routes. However, the context most likely to precipitate unstable angina in susceptible patients is the creation of a microenvironment where fossil fuels are burnt in poorly ventilated areas. The kerosene heater used injudiciously is one example, but motor vehicles idling in enclosed spaces or people caught up in fires could represent likely scenarios.

The treatment of cases similar to the three described should include $100 \%$ oxygen so as to rapidly lower the circulating levels of carboxyhaemoglobin thus diminishing the severity and the duration of the myocardial ischaemia. Hyperbaric therapy is probably not useful in these cases for practical reasons. It can take around an hour to organize by which time circulating carboxyhaemoglobin levels would have been greatly reduced by oxygen therapy. 


\section{Conclusion}

Unstable angina is one form of presentation of carbon monoxide poisoning. Carboxyhaemoglobin levels of $15-20 \%$ were detected in two patients with underlying coronary artery disease. Patients routinely admitted to coronary care with unstable angina should be questioned about possible exposure to carbon monoxide. Carboxyhaemoglobin levels should be determined when this

\section{References}

1. Winter, P.M. \& Miller, J.N. Carbon monoxide poisoning. JAMA 1976, 236: 1502-1504.

2. Ehrich, W.E., Bellet, S. \& Lewey, F.H. Cardiac changes in carbon monoxide poisoning. Am J Med Sci 1944, 208: 511-521.

3. Ayers, S.M., Giannelli, S. \& Muller, H. Myocardial and systemic response to carboxy-hemoglobin. Ann NY Acad Sc 1970, 174: 268-293.

4. Schafer, N., Smilay, M.G. \& Mcmillan, F.P. Primary myocardial disease in man resulting from acute carbon monoxide poisoning. Am J Med 1965, 38: 316-320.

5. Anderson, R.F., Allensworth, D.C. \& Degroot, W.J. Myocardial toxicity from carbon monoxide poisoning. Ann Intern Med 1967, 67: 1172-1182.

6. Allred, E.N., Bleecker, E.R., Chaitman, B.R., Dahms, T.E., Gottlieb, S.D., Hackney, J.D. et al. Short term effect of carbon monoxide on exercise performance of subjects with coronary artery disease. $N$ Engl J Med 1989, 321: 1426-1432.

7. Anderson, E.W., Andelman, R.S., Strauch, J.M., Fortuin, N.S. \& Knelson, J.H. Effect of low level carbon monoxide exposure on onset and duration of angina pectoris. A study of ten patients with ischemic heart disease. Ann Intern Med 1973, 79: 46-50. is suspected so as to allow prompt treatment with oxygen in high concentration.

\section{Acknowledgement}

We acknowledge with thanks the contribution of the staff at the Emergency Laboratory, St Luke's Hospital, particularly Ralph Camilleri, B.Sc., A.I.B.M.S.

8. Aronow, W. \& Isbell, M.W. Carbon monoxide effect on exercise induced angina pectoris. Ann Intern Med 1973, 79: 392-395.

9. Aronow, W.S. Aggravation of angina pectoris by $2 \%$ carboxy-hemoglobin. Am Heart J 1981, 101: 154.

10. Aronow, W.S. Effect of passive smoking on angina pectoris. $N$ Engl J Med 1978, 299: 21-24.

11. Grace, T.N. \& Platt, F.W. Sub-acute carbon monoxide poisoning. JAMA 1981, 246: 1698-1700.

12. Theroux, P., Ouimet, H., McCans, J. et al. Aspirin, heparin, or both to treat acute unstable angina. $N$ Engl J Med 1988, 319: $1105-1111$.

13. Stewart, R.D., Baretta, E.D., Platte, L.R. et al. Carboxyhemoglobin levels in American blood donors. JAMA 1974, 229: $1187-1195$.

14. Scarf, S.M., Thames, M.D. \& Sargent, R.K. Transmural myocardial infarction after exposure to carbon monoxide in coronary artery disease. $N$ Engl Med 1974, 291: 85-86.

15. Wald, N., Idle, M., Smith, P.G. \& Bailey, A. Carboxy haemoglobin levels in smokers of filter and plain cigarettes. Lancet 1977 , i: $110-111$. 